\title{
FIR Low Pass Filter Designing using Bartlett Hanning, Blackman Harris and Nuttal Window Techniques
}

\author{
Suman Mahant ${ }^{1}$, Pooja Singh Chandel ${ }^{2}$, Pranay Kumar Rahi ${ }^{3}$ \\ B.E. Scholar, Department of Electrical and Electronics Engg, Institute of Technology, Korba Chhattisgarh, India ${ }^{1,2}$
} Assistant Professor, Department of Electrical and Electronics Engg, Institute of Technology, Korba Chhattisgarh, India ${ }^{3}$

\begin{abstract}
Digital filter plays a significant role in the advanced area of communication system as it provides high attenuation to the unwanted signals and at same time offers very low attenuation to the desired signals. In this paper, Low pass filter is designed using different window techniques namely Bartlett Hanning, Blackman Harris and Nuttal. Design of FIR filter is done in MATLAB by FDATOOL low pass filter is designed with sampling frequency $48000 \mathrm{~Hz}$ and cut-off frequency $10000 \mathrm{~Hz}$ magnitude, phase impulse, step response and pole, zero plot. Here the Magnitude and phase response in time and frequency domain ofthese window techniques have been compared using MATLAB simulation.
\end{abstract}

Index Terms: FIR, Digital filter, DSP, Low pass filter, MATLAB, FDATOOL in MATLAB, Bartlett Hanning Window, Blackman Harris Window, Nuttal Window techniques.

\section{INTRODUCTION}

Digital signal processing is an area of science and There are two types of filters i.e. engineering that has developed rapidly over the past 40 1. Finite Impulse Response (FIR) filter years. This rapid development is a result of the significant 2. Infinite Impulse Response (IIR) filter advances in digital computer technology and integrated circuit fabrication [2]. It comprises the presentation, evaluation, transformation and manipulation of signals. This signal processing measures can, for instants, serve efficient storage and transmission of signal. Digital filters play animportant role in digital signal processing applications. A digital filter is a mathematical algorithm implemented in hardware / software that operates on a digital input to produce a digital output. In signal processing, a filter is Digital filter are important class of Linear time invariant DSP systems designed to modify the frequency characteristics of the input signal $\mathrm{x}(\mathrm{n})$ to meet certain specific design requirements. Digital filters are widely used because of certain advantages over Analog filters. Digital filters have the potential to attain much better signal to noise ratios than Analog filters. Digital Filters have emerged as a strong option [1].

Signal processing is a method of extracting information from signal $m$ the signal which in turn depends on the type of signal and the nature of information it carries. Thus signal processing is concerned with representing signals in mathematical terms and extracting the information by carrying out the algorithmic operation on the signal [1].

Infinite Impulse Response (IIR) digital filter has the problems of phase non-linearity. Therefore it is a low order filter which becomes highly unstable. Due to these factors, the Finite Impulse response (FIR) filter can be used to design a linear phase digital filter which is convenient for image processing and data transmission applications [3]. As compare to IIR filter, the FIR filter is a non-recursive (without feedback) structure, finite precision mathematical error is very small, while IIR filter is recursive (with feedback) structure and parasitic oscillation may occur because of IIR filter. FIR filter gives better amplitude and linear phase characteristics and also avoid the drift, noise and distortion as compare to IIR filters [4].

Digital signal Processing is used in various applications such as digital set top box, cable modems, video compression, robotic vision, image enhancement, facsimile, speech recognition, radar processing, spread spectrum, digital cameras, ECG, EEG[3].

Table 1: Types of filter (response)

\begin{tabular}{|c|c|c|c|}
\hline SN & Type of Filter & Duration & $\begin{array}{c}\text { No. of non- } \\
\text { zero term }\end{array}$ \\
\hline 1. & IIR FILTER & Finite & Finite \\
\hline 2. & IIR FILTER & Infinite & Infinite \\
\hline
\end{tabular}

FIR filters have the following advantages over IIR filters-

1. They can have an exact linear phase.

2. They are always stable.

3. The design methods are generally linear.

4. They can be realised efficiently in hardware.

5. The filter start-up transients have finite duration. 
FIR filters are employed in filtering problems where linear phase characteristics within the passband of the filter are required. If this is not required, either an IIR or an FIR filter may be employed. An IIR filter has lesser number of side lobes in the stopband that an FIR filters with the same number of parameters. For this reason, if some phase distortion is tolerable, an IIR filter is preferable. Also, the implementation of an IIR involves fewer parameters, less memory requirements and lower computational complexity [1].

\section{WINDOW TECHNIQUES}

\subsection{BARTLETT HANNING WINDOW}

\section{FUNCTION}

The window function of Bartlett Hanning window is expressed by

$$
\mathbf{w}(\mathbf{n})=\mathbf{a}_{0}-\mathbf{a}_{1}\left|\frac{\mathbf{n}}{\mathrm{N}-1}-\frac{1}{2}\right|-\mathbf{a}_{2} \cos \left(2 \pi \frac{2 \pi n}{\mathrm{~N}-1}\right)
$$

\subsection{BLACKMAN HARRIS WINDOW FUNCTION}

The equation for the symmetric 4-term BlackmanHarriswindow of length $\mathrm{N}$ is

$$
\begin{gathered}
w(n)=a_{0}-a_{1} \cos \left(\frac{2 \pi n}{N-1}\right)+a_{2} \cos \left(\frac{4 \pi n}{N-1}\right)-a_{3} \\
\cos \left(\frac{6 \pi n}{N-1}\right) \quad 0 \leq n \leq N-1
\end{gathered}
$$

The equation for the periodic 4-term Blackman-Harris window of length $\mathrm{N}$ is

$$
\begin{gathered}
w(n)=a_{0}-a_{1} \cos \left(\frac{2 \pi n}{N}\right)+a_{2} \cos \left(\frac{4 \pi n}{N}\right)-a_{3} \\
\cos \left(\frac{6 \pi n}{N}\right) \quad 0 \leq n \leq N-1
\end{gathered}
$$

The periodic window is $\mathrm{N}$-periodic. The following table lists the coefficients:

Table 2: Coefficient of Blackman Harris window

\begin{tabular}{|c|c|}
\hline Coefficient & Value \\
\hline $\mathrm{a}_{0}$ & 0.35875 \\
\hline $\mathrm{a}_{1}$ & 0.48829 \\
\hline $\mathrm{a}_{2}$ & 0.14128 \\
\hline $\mathrm{a}_{3}$ & 0.01168 \\
\hline
\end{tabular}

\subsection{Nuttall Window}

The Nuttall window has the widest main lobe and lowest maximum side lobe level among the Blackman, ExactBlackman and the Blackman-Harris window. The equation for the Nuttall window is

$$
\begin{gathered}
w(n)=a_{0}-a_{1} \cos \left(2 \pi \frac{n}{N-1}\right)+a_{2} \cos \left(4 \pi \frac{n}{N-1}\right)-a_{3} \\
\cos \left(6 \pi \frac{n}{N-1}\right) \ldots \ldots \ldots \ldots
\end{gathered}
$$

Where $\mathrm{n}=0,1,2, \ldots \mathrm{N}-1$

The equation for the periodic Nuttall

$$
\begin{gathered}
w(n)=a_{0}-a_{1} \cos \left(2 \pi \frac{n}{N}\right)+a_{2} \cos \left(4 \pi \frac{n}{N}\right)-a_{3} \\
\cos \left(6 \pi \frac{n}{N}\right) \ldots \ldots \ldots \ldots \ldots
\end{gathered}
$$

where $\mathrm{n}=0,1,2, \ldots \mathrm{N}-1$. The periodic window is $\mathrm{N}$ periodic.

The coefficients for this window are given in table

Table 3: Coefficient of Nuttall window

\begin{tabular}{|c|c|}
\hline Coefficient & Value \\
\hline $\mathrm{a}_{0}$ & 0.3635819 \\
\hline $\mathrm{a}_{1}$ & 0.4891775 \\
\hline $\mathrm{a}_{2}$ & 0.1365995 \\
\hline $\mathrm{a}_{3}$ & 0.0106411 \\
\hline
\end{tabular}

\section{DESIGN SIMULATION}

To design the low pass FIR filter using MATLAB Bartlett Hanning, Blackman Harris and Nuttal Window the parameter specifications are given in table 2 . As

Table 4: Parameter Specification

\begin{tabular}{|c|c|}
\hline PARAMETER & VALUE \\
\hline Sampling Frequency $\left(\mathrm{f}_{\mathrm{s}}\right)$ & $48000 \mathrm{~Hz}$ \\
\hline Cut off Frequency $\left(\mathrm{f}_{\mathrm{c}}\right)$ & $10800 \mathrm{~Hz}$ \\
\hline Order $(\mathrm{N})$ & 20 \\
\hline
\end{tabular}

Table 5: Frequency and magnitude

\begin{tabular}{|c|c|c|c|}
\hline Frequency & \multicolumn{3}{|c|}{ Window Technique } \\
\hline $\mathrm{kHz}$ & $\begin{array}{c}\text { Bartlett } \\
\text { Hanning }\end{array}$ & $\begin{array}{c}\text { Blackman } \\
\text { Harris }\end{array}$ & $\begin{array}{c}\text { Nuttal } \\
\text { Magnitude }\end{array}$ \\
\hline 1 & 0.0062 & -1.8707 & -6.7056 \\
\hline 2 & 0.0107 & -0.0002 & -0.0004 \\
\hline 3 & -0.0036 & -0.0048 & -0.0036 \\
\hline 4 & -0.0245 & -0.0233 & -0.0224 \\
\hline 5 & -0.0162 & -0.0978 & -0.0877 \\
\hline 6 & 0.0101 & -0.2968 & -0.2668 \\
\hline 7 & -0.0718 & -0.6818 & -0.6636 \\
\hline 8 & -0.5089 & -1.3980 & -1.3632 \\
\hline 9 & -1.5485 & -2.5444 & -2.4949 \\
\hline 10 & -3.5321 & -4.2088 & -4.1636 \\
\hline
\end{tabular}

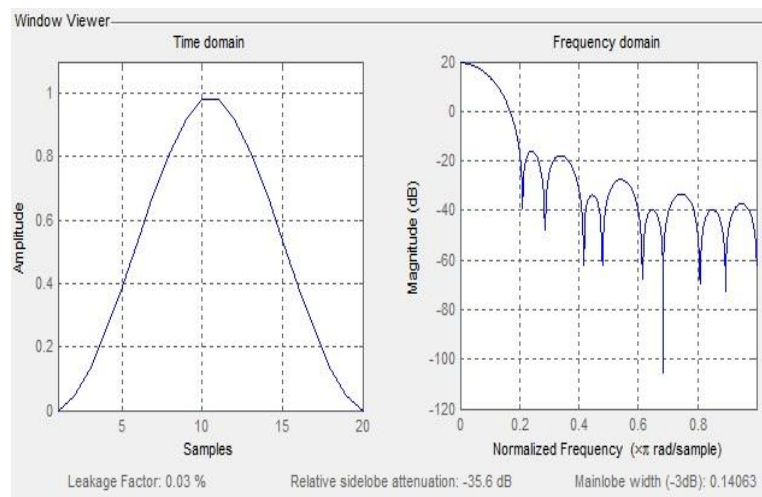

Figure (1): Time Domain and Frequency Domain of Bartlett Hanning window technique 
Vol. 6, Issue 3, March 2017

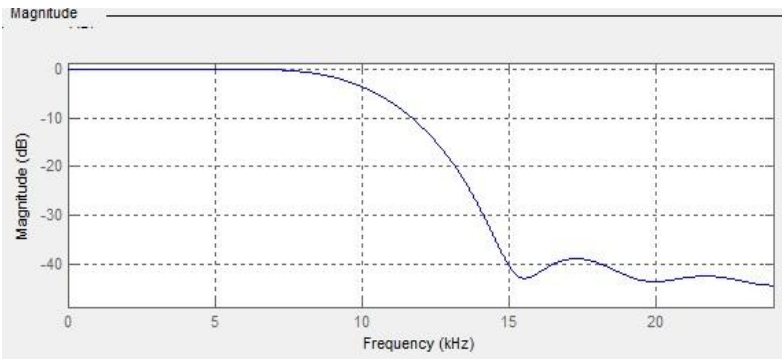

Figure (2): Magnitude Response of Bartlett Hanning window technique

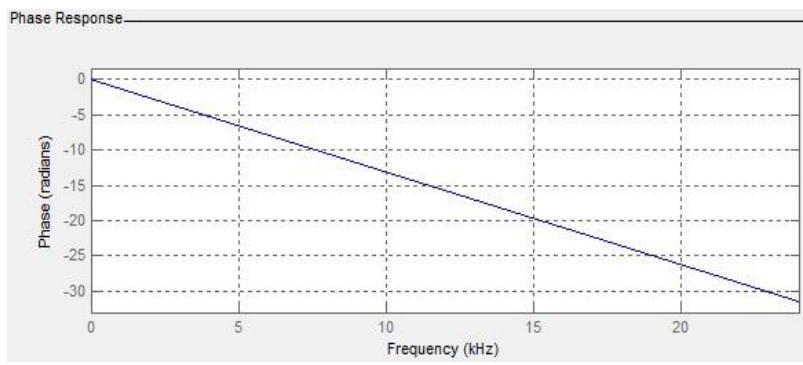

Figure (3): Phase Response of Bartlett Hanning window technique

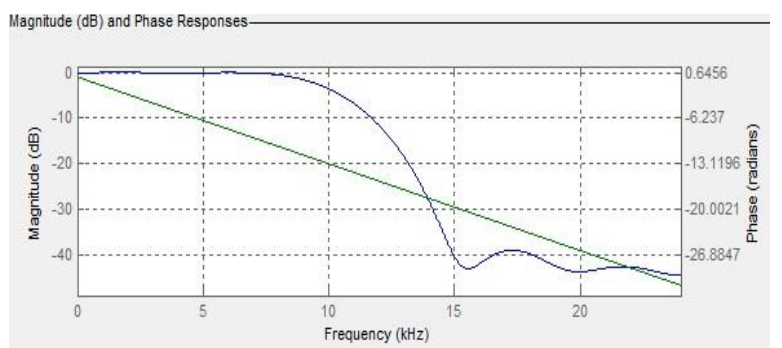

Figure (4): Magnitude and Phase Response of Bartlett Hanning window technique

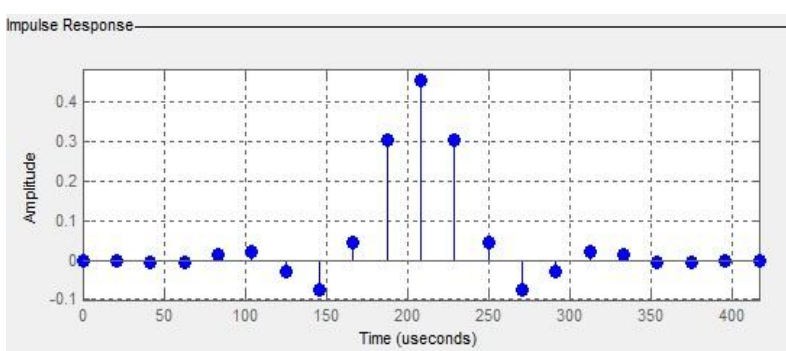

Figure (5): Impulse Response of Bartlett Hanning window technique

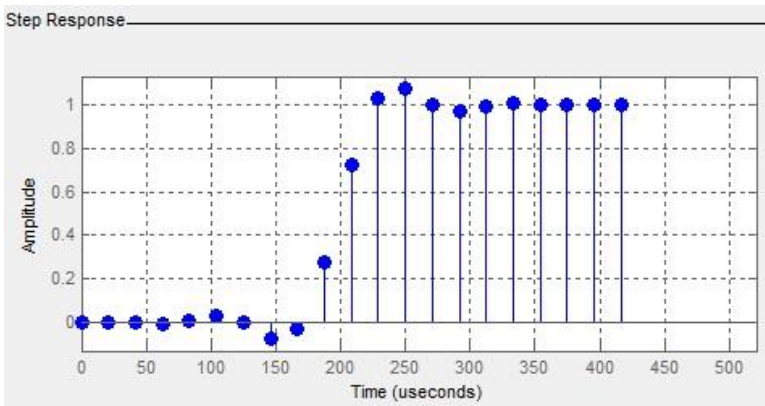

Figure (6): Step Response of Bartlett Hanning window technique

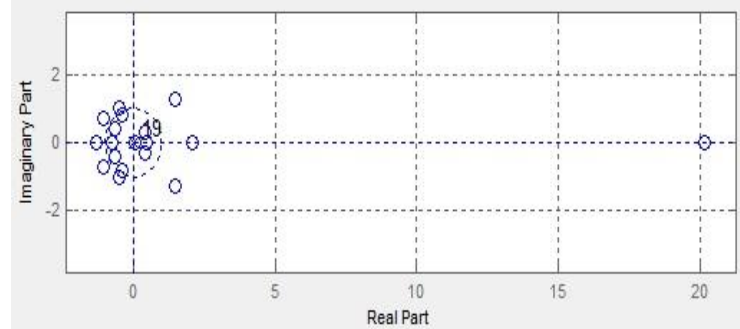

Figure (7): Pole Zero Plot of Bartlett Hanning window technique

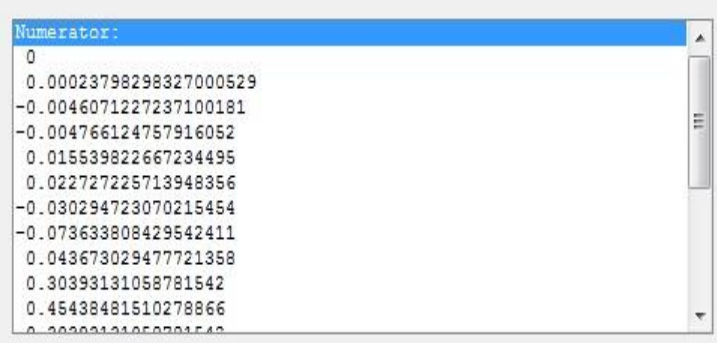

Figure (8): Filter Coefficient of Bartlett Hanning window technique

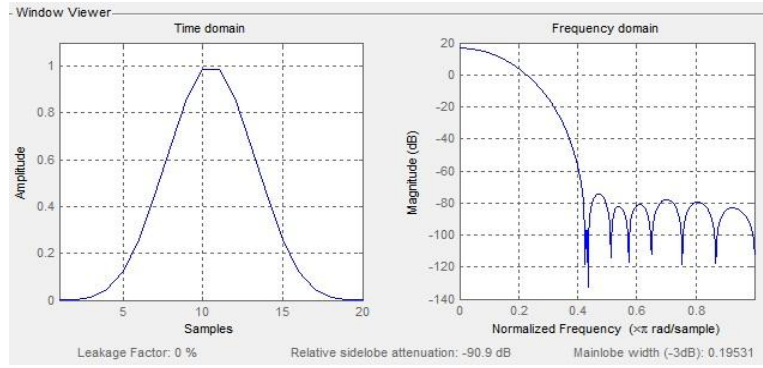

Figure (9): Time Domain and Frequency Domain of Blackman Harris window technique

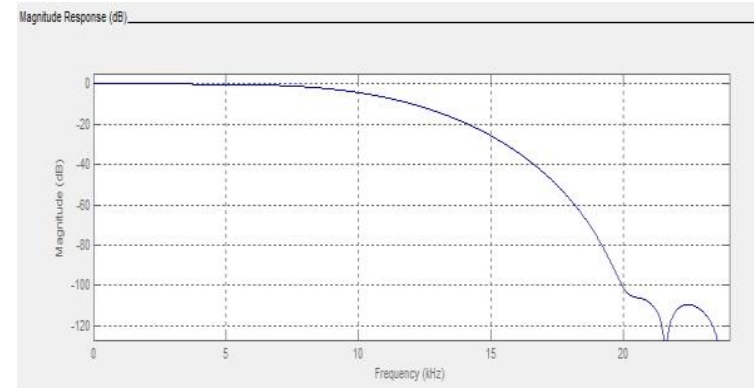

Figure (10): Magnitude Response of Blackman Harris window technique

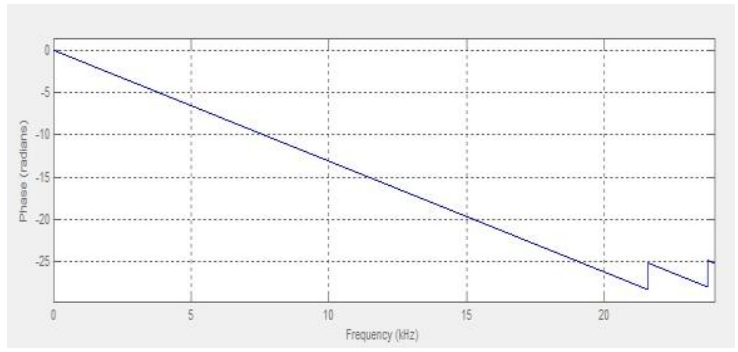

Figure (11): Phase Response of Blackman Harris window technique 
Vol. 6, Issue 3, March 2017

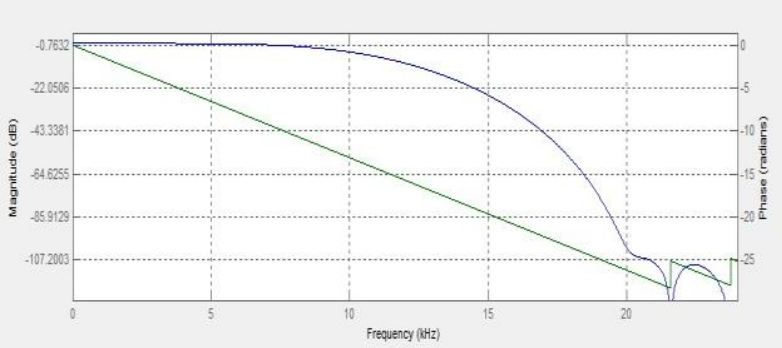

Figure (12): Magnitude and Phase Response of Blackman Harris window technique

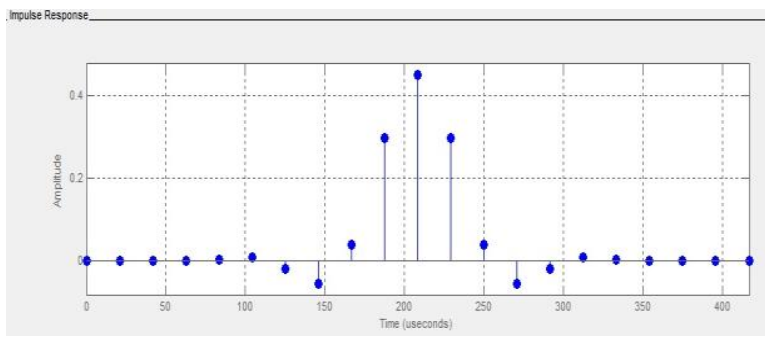

Figure (13): Impulse Response of Blackman Harris window technique

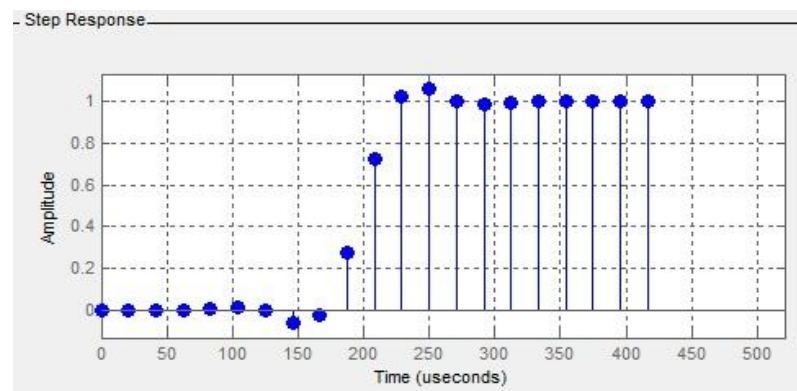

Figure (14): Step Response of Blackman Harris window technique

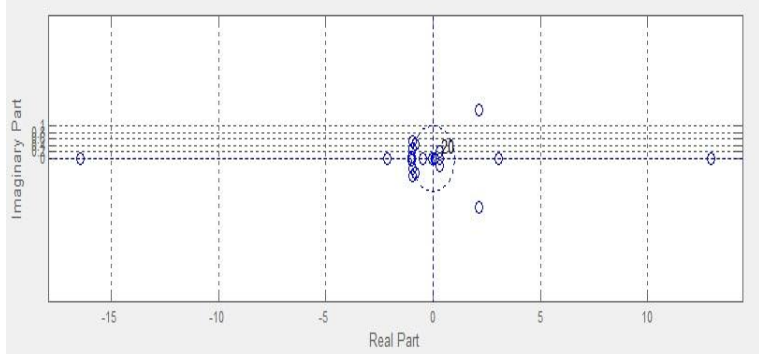

Figure (15): Pole Zero Plot of Blackman Harris window technique

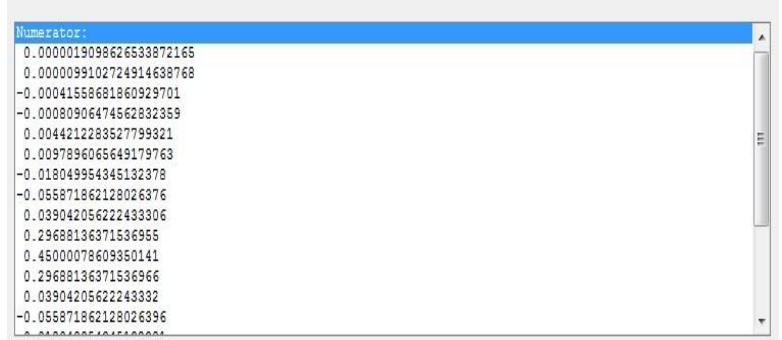

Figure (16): Filter Coefficient of Blackman Harris window technique

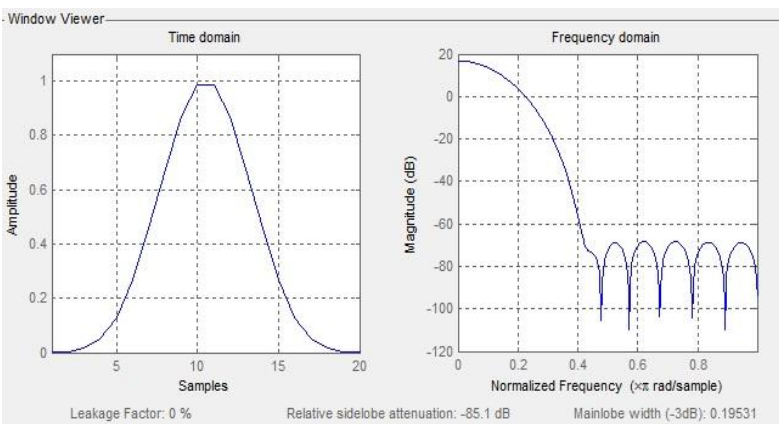

Figure (17): Time Domain and Frequency Domain of Nuttal window technique

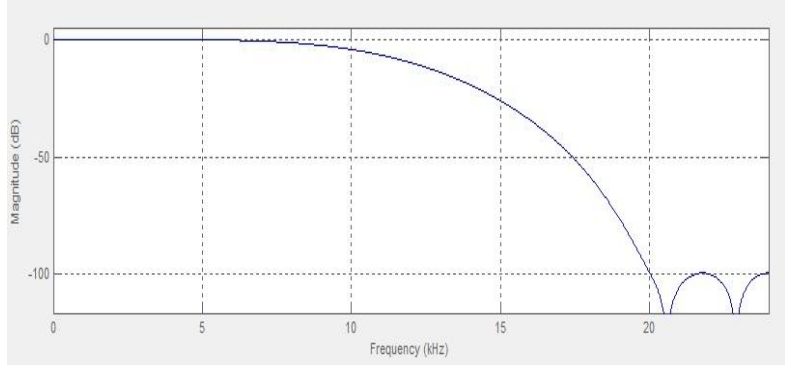

Figure (18): Magnitude Response of Nuttal window technique

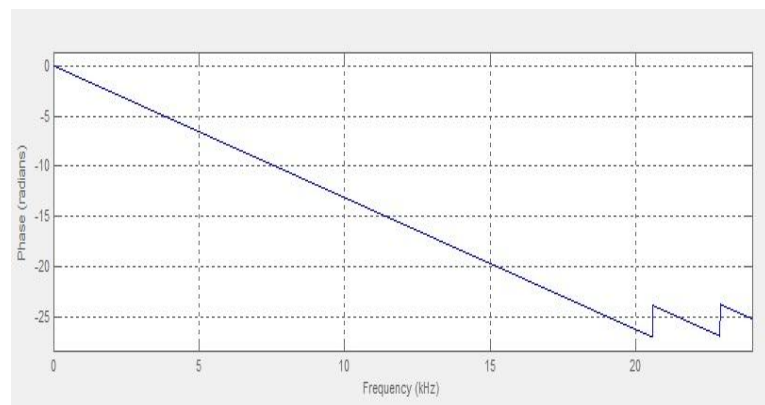

Figure (19): Phase Response of Nuttal window technique

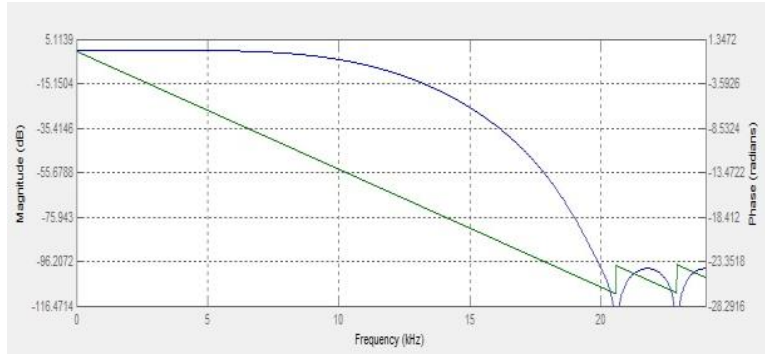

Figure (20): Magnitude and Phase Response of Nuttal window technique

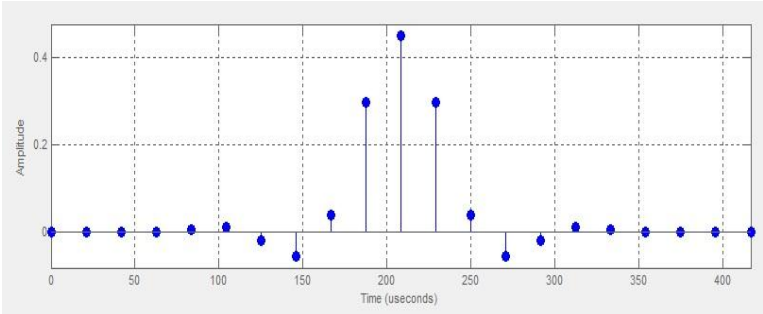

Figure (21): Impulse Response of Nuttal window technique 
Vol. 6, Issue 3, March 2017

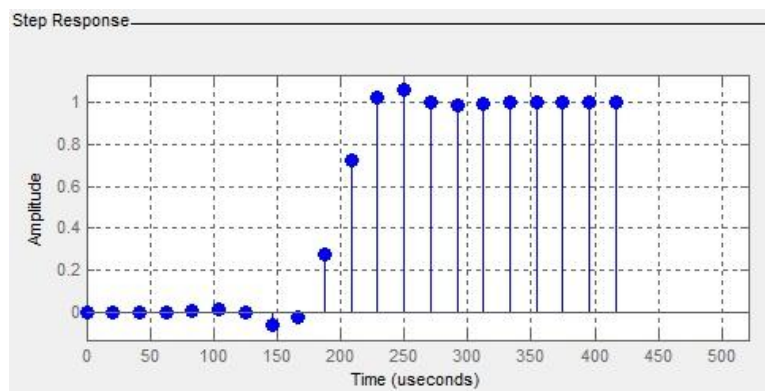

Figure (22): Step Response of Nuttal window technique

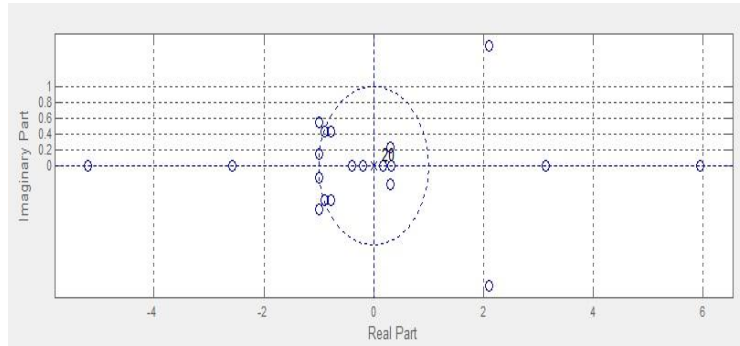

Figure (23): Pole Zero Plot of Nuttalwindow technique

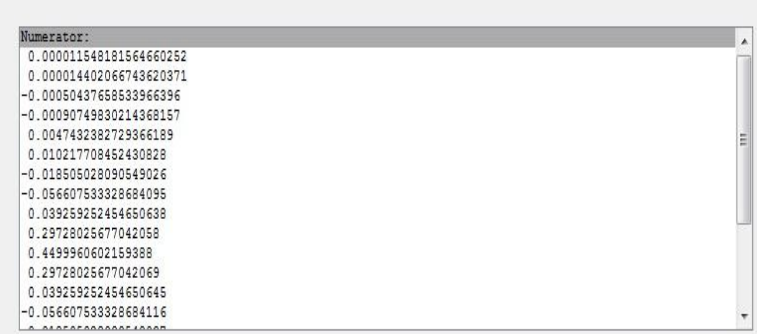

Figure (24): Filter Coefficient of Nuttal window technique

\section{COMARARTIVE ANALYSIS}

Bartlett Hanning and Blackman Harris windows techniques are used along with Nuttal windows techniques for design analysis and comparison by using matlabs.

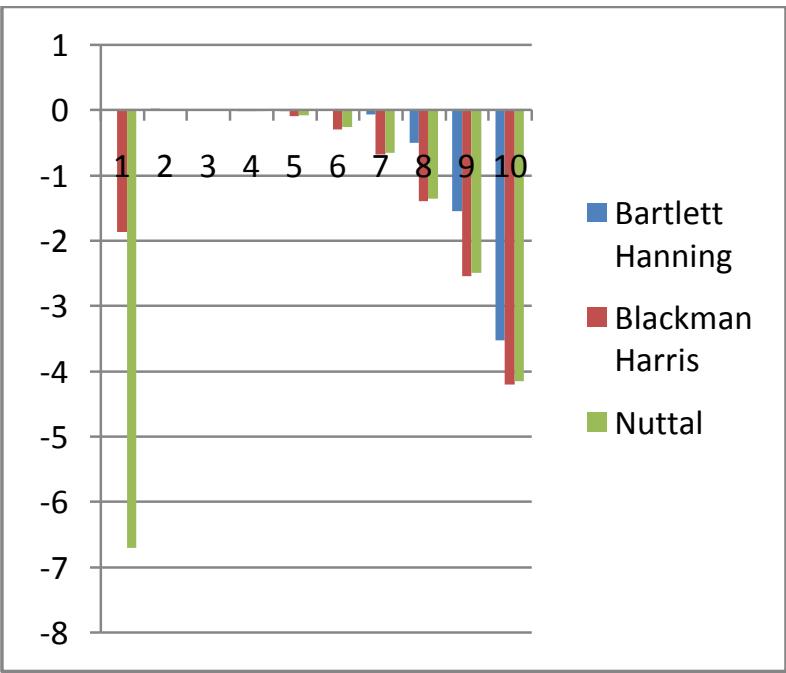

Figure (25): Magnitude and Frequency Plot of Bartlett Hanning, Blackman Harris and Nuttal window techniques

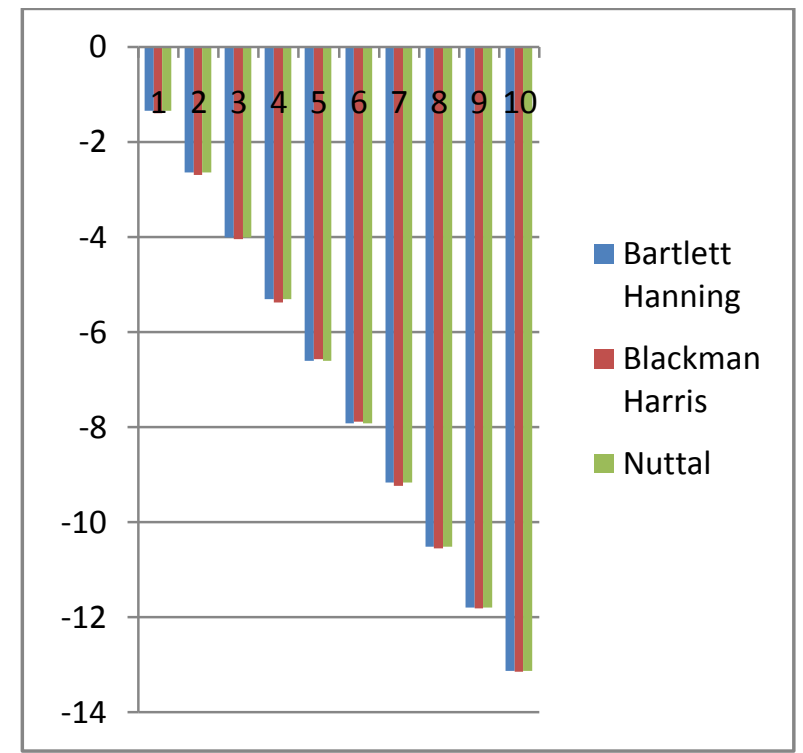

Figure (26): Phase and Frequency Plot of Bartlett Hanning, Blackman Harris and Nuttal window techniques

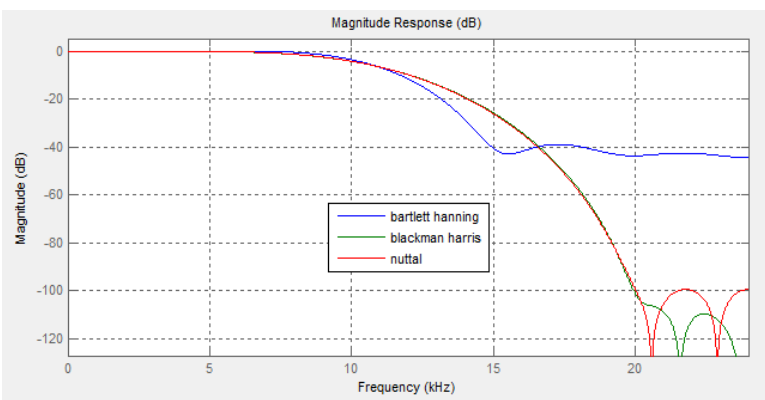

Figure (27): Magnitude comparison of Bartlett Hanning, Blackman Harris and Nuttal window techniques

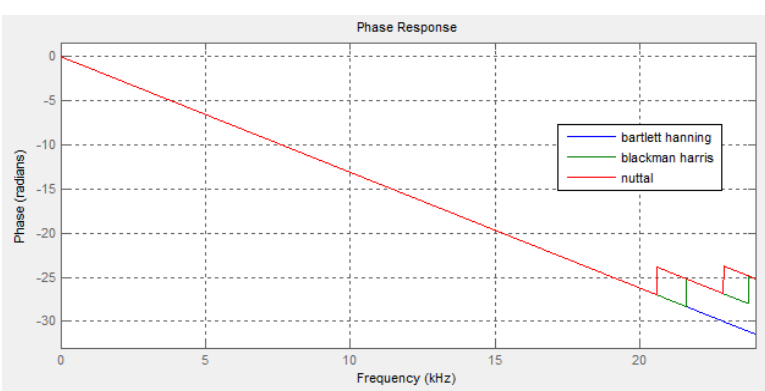

Figure (28): Phase comparison of BartlettHanning, Blackman Harris and Nuttal window technique

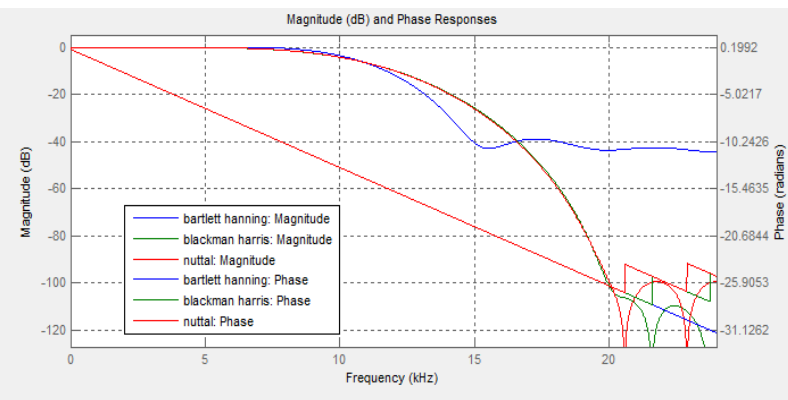

Figure (29): Magnitude and Phase comparison of Bartlett Hanning, Blackman Harris and Nuttal 


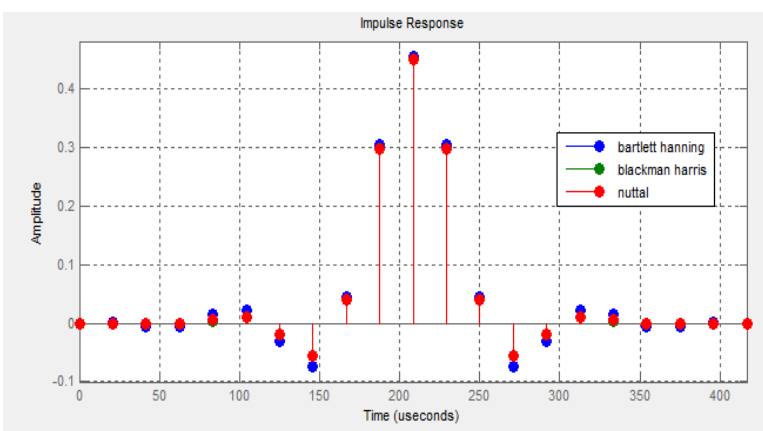

Figure (30): Impulse Response of Bartlett Hanning, Blackman Harris and Nuttal window technique

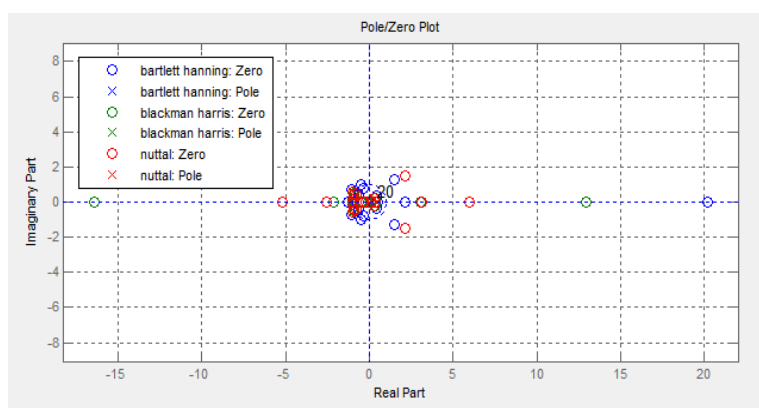

Figure (31): Pole Zero Plots of Bartlett Hanning, Blackman Harris and Nuttal window technique

\section{RESULT}

Table 6: Simulation Result in MATLAB

\begin{tabular}{|l|l|l|l|}
\hline $\begin{array}{l}\text { Window } \\
\text { Technique }\end{array}$ & $\begin{array}{l}\text { Leakage } \\
\text { Factor }\end{array}$ & $\begin{array}{l}\text { Relative } \\
\text { sidelobe } \\
\text { attention }\end{array}$ & $\begin{array}{l}\text { Mainlobe } \\
\text { width } \\
(-3 \mathrm{~dB})\end{array}$ \\
\hline Bartlett Hanning & 0.03 & $-35.6 \mathrm{~dB}$ & 0.14063 \\
\hline Blackman Harris & 0 & $-90.9 \mathrm{~dB}$ & 0.19531 \\
\hline Nuttal & 0 & $-85.1 \mathrm{~dB}$ & 0.19531 \\
\hline
\end{tabular}

\section{CONCLUSIONS}

In this research paper, Low pass filter has been designed and simulated using three different Window Techniques namely Bartlett Hanning, Blackman Harris and Nuttal. After analysing the performance of proposed FIR filter by their magnitude and phase response using MATLAB simulation at same values of sampling frequency $48 \mathrm{kHz}$, cut off frequency $10.8 \mathrm{kHz}$ and order of 20 , we conclude that Nuttal window has better pass band response as compared to Bartlett Hanning and Blackman Harris Window. So it is clear that Nuttal window technique is more powerful and perfect than the FIR filter designed with other windows i.e. Bartlett Hanning, Blackman Harris and Nuttal.

\section{REFERENCES}

1) S Salivahanan and C Ghanapriya, "Digital Signal Processing", Tata McGraw -Hill, $2^{\text {nd }}$ Edition, 2010.
2) John G. Proakis, Dimitris G. Manolakis, "Digital Signal Processing Principles, Algorithms and Applications", PEAESON, $4^{\text {th }}$ Edition, 2008.

3) ${ }^{1}$ Ghulam Ahmad Raza, ${ }^{2}$ Rajesh Mehra ${ }^{1}$ M.E. Scholar, ${ }^{2}$ Associate Professor ${ }^{1,2}$ Department of Electronics \& Communication Engineering National Institute of Technical Teachers Training \& Research Chandigarh, UT, India (High Pass Filter Design and Analysis Using Nuttall and Parzen Windows)

4) Mohd. ShariqMahoob, Rajesh Mehra, "Design of Low Pass FIR Filter using Hamming, Blackman-Harris and Taylor" IJARSE, Vol. No.3, Issue No.11, ISSN-2319-8354(E) November 2014.

5) ShikhaShukla, Kamal Prasad Pandey, Rakesh Kumar Singh, "Implementation and Simulation of Low Pass Finite Impulse Response Filter Using Different Window Method" IJETAE, ISSN 2250-2459, Vol. 5, Issue 1, January 2015.

6) Manoj Chandra Dey, ${ }^{1}$ Smriti Baxla ${ }^{2}$, Pranay Kumar $\mathrm{Rahi}^{3}$, Muzaherul Haque ${ }^{41,2}$ Lecturer $^{3,4}$ Assistant Professor, ${ }^{1,2,3,4}$ Department of Electrical and Electronics Engineering, Institute of Technology, Korba Chhattisgarh, India.( Design and Performance Analysis of Low Pass Fir Filter Using Different Windows Techniques).

\section{BIOGRAPHIES}

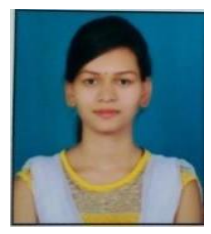

Suman Mahant pursuing bachelor of Engineering in Electrical and Electronics Engineering in $6^{\text {th }}$ semester, from Institute of Technology Korba, Chhattisgarh Swami Vivekananda Technical University, Chhattisgarh, India.

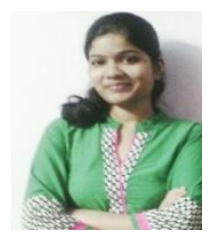

Pooja Singh Chandel pursuing bachelor of Engineering in Electrical and Electronics Engineering in 6th semester, from Institute of Technology Korba, Chhattisgarh Swami Vivekananda Technical University, Chhattisgarh, India.

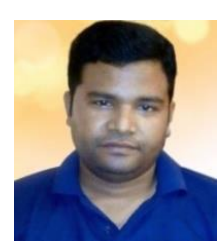

Pranay Kumar Rahi received the bachelor of technology degree in Electronics and Telecommunication engineering collage, guru ghashidas university, bilaspur Chhattisgarh, india in 2004, and persuing master of engineering in electronics and communication engineering from national institute of technical teacher's training \& research, Punjab University, Chandigarh, india. Presently working as assistant professor in department of electrical and electronics engineering, institute of technology, korba Chhattisgarh since 2008. He has authored more than 40 research publications and published journal paper and research papers in the leading international and national journal. This primary research interest includes digital signal processing, VLSI design, control systems and digital electronics and logic design. 